\title{
Serological screening suggests that adult coeliac disease is underdiagnosed in the UK and increases the incidence by up to $12 \%$
}

\author{
D J Unsworth, D L Brown
}

\begin{abstract}
Because coeliac disease often presents atypically it is underdiagnosed. It is suggested that the detection rate may be increased by $12 \%$ if serology is used to identify cases of occult enteropathy. All adults noted incidentally to be $R 1$ anti-reticulin antibody (ARA) positive in the course of routine autoantibody testing of 6532 sera over one year were followed. None of the eight patients with seropositive serum was suspected of having coeliac disease. All eight had high titres of IgA anti-gliadin and IgA anti-endomysial antibodies, neither of which is detected in a routine autoantibody test, in addition to IgA R1-ARA. On clinical review coeliac disease was considered probable in only one patient, but because of the strong serological evidence of gluten sensitivity, jejunal biopsy was advised in all eight. Seven agreed and all had villous atrophy and crypt hyperplasia in keeping with coeliac disease. Six of the seven presented initially with vague symptoms such as tiredness or arthralgia. These symptoms disappeared after several weeks of gluten withdrawal. Forty two sera showing reticulin staining patterns other than $R 1$ were used as controls. Low titre IgA anti-gliadin was noted in two of 42 but none had IgA anti-endomysial antibody. These 42 cases were not recommended for biopsy. During our study 58 other new adult cases of coeliac disease were diagnosed, primarily on clinical rather than serological grounds, at the four hospitals that request autoantibody studies. Occult coeliac disease detected serologically thus increased the overall incidence of coeliac disease by $12 \%$ from 58 to 65 cases. R1-ARA, even in the absence of the expected symptoms and signs of coeliac disease, is an indication for jejunal biopsy and is a reliable indicator of occult coeliac disease.

(Gut 1994; 35: 61-64)
\end{abstract}

IgA anti-endomysial antibody is useful when selecting suspected cases of coeliac disease for confirmatory biopsy. ${ }^{12}$ Anti-reticulin antibody of the R1 type (R1-ARA), however, which also is known to be strongly associated with untreated gluten sensitive enteropathy, ${ }^{3}$ has been regarded as less useful because its sensitivity for coeliac disease is only $50 \%{ }^{4}$ and its specificity for this disorder is questioned. ${ }^{56}$ Sensitivity and specificity of $97 \%$ and $98 \%$ respectively are claimed when the conventional test is adapted to detect IgA R1-ARA. ${ }^{7}$ Nonetheless, doubts over the reliability of the R1-ARA test have meant that it is now hardly ever requested in its own right. R1-ARA is occasionally discovered in the course of routine autoantibody testing using cryostat sections of rodent tissue as substrate. It is important to note that anti-endomysial and anti-gliadin antibody do not show up in this conventional autoantibody test. Patients in whom RI-ARA is found fortuitously may have none of the expected symptoms or signs of gluten sensitive enteropathy. In some cases a firm alternative diagnosis has already been made, and these patients may be presumed to represent 'false positives'. Untreated coeliac disease carries an increased risk of malignancy ${ }^{8}$ and there are therefore sound medical and ethical reasons why cases of unsuspected disease should be diagnosed and treated. In this study we show that IgA R1-ARA is reliable and valuable in assisting the early recognition and treatment of occult coeliac disease.

\section{Patients and methods}

Altogether 6532 adult sera were tested in our routine autoantibody test in the 12 months from July 1991 to June 1992 . We receive very few requests for autoantibody studies on children, and these were excluded from our study. Ninety two per cent of the sera came from four hospitals in the East Anglia region - namely Hinchinbrooke (Huntingdon); The West Suffolk (Bury St Edmunds); Addenbrooke's, Cambridge; and the Norfolk and Norwich. These hospitals together serve a population of approximately $1 \cdot 16$ million. Only $16 \%$ of the requests came from people suspected of gastroentestinal disease, particularly autoimmune liver disease. Patients known or suspected at the time of autoantibody testing to have coeliac disease were excluded from our study.

Diagnosis of coeliac disease was based on jejunal biopsy specimen showing the appropriate histopathological features, and clinical improvement on a gluten free diet, in keeping with the recently revised diagnostic criteria. ${ }^{9}$ Five of the seven patients with R1-ARA seropositivity agreed to undergo confirmatory biopsy between three and six months after starting a gluten free diet, and all five showed considerable histological improvement. Full blood counts, liver enzyme activities, and albumen and calcium were measured in all cases before starting a gluten free diet. Serum iron or ferritin, or both, and serum and red cell folate were measured in five patients before gluten free diet. Because no patient had diarrhoea, measurement of faecal fat loss was not indicated. The total number of newly presenting adults with coeliac disease at 
the four hospitals during this one year study was determined by consultation with the gastroenterologists and histopathologists at those hospitals. Local population numbers are from mid-1990 census data to the nearest 10000 .

\section{METHODS}

Indirect immunofluorescence for ARA was performed as previously described, ${ }^{4}$ with cryostat sections $(6 \mu)$ of a composite block of rat tissues as substrate and patient's sera diluted $1 / 10$ in phosphate buffered saline (PBS). ARA positive sera were subdivided into five groups - R1, partial R1, R2, Rs (sinusoidal), and heterophile, according to the pattern of immunofluorescence staining seen when using a polyvalent antiimmunoglobulin reagent. All ARA positive sera were retested using IgA and IgG specific reagents. The five $R 1$, five partial $R 1$, and $15 R 2$ positive sera represented the total number that showed these reactivities over the year. The remaining 25 sera studied showed Rs or heterophile patterns and were collected over a two month period. Forty two sera were ultimately classed as non- $\mathrm{R} 1$ after isotype specific testing and these served as the control group. Four of these 42 sera had been sent to us by other laboratories for an opinion on whether they were R1-ARA positive.

The R1 and R2 patterns were as defined by Rizzetto and Doniach. ${ }^{10} \mathrm{R} 1$ positive sera were required to stain fibrillar connective tissue extensively in rat liver, kidney, and stomach. Sera failing to stain any one of these three tissues but giving $\mathrm{R} 1$ staining in the remaining tissues were classified as showing a partial R1 pattern. Staining of discrete thread like reticulin fibrils in rat liver parenchyma was the most distinctive and reliable feature of the $\mathrm{R} l$ antibody. Rs positive sera stained liver sinusoids, and in most cases kidney tubule brush border and stomach submucosal reticulin fibres also, but failed to give $R \mathbf{l}$ staining in the kidney and between the gastric parietal cells. The Rs group includes the antisinusoid and anti-Kupffer cell reactivities reported by Rizzetto and Doniach. ${ }^{10}$ Heterophile antibodies stained gastric parietal cells and kidney tubule brush border, and gave R1-ARA like staining restricted to kidney medulla.

Anti-endomysial antibody was detected in sera diluted $1 / 10$ in PBS on slides of monkey oeso-

TABLE I Clinical, haematological, and histopathological details on the eight R1-anti-reticulin antibody positive patients

\begin{tabular}{|c|c|c|c|c|c|c|}
\hline $\begin{array}{l}\text { Case } \\
\text { no }\end{array}$ & $\begin{array}{l}\text { Sexl } \\
\text { age }(y)\end{array}$ & $\begin{array}{l}\text { Presenting } \\
\text { complaint }\end{array}$ & $\begin{array}{l}\text { Reason for auto- } \\
\text { antibody test }\end{array}$ & $\begin{array}{l}\text { Haemoglobin } \\
(\mathrm{g} / \mathrm{l})\end{array}$ & Haematinics & $\begin{array}{l}\text { Small } \\
\text { intestinal } \\
\text { biopsy }\end{array}$ \\
\hline 1 & M/45 & Swollen wrist & Arthralgias & $15 \cdot 1$ & ND & PVA \\
\hline 2 & $\mathrm{~F} / 79$ & Swollen ankles ${ }^{\star \star}$ & Abnormal LFT & $7 \cdot 8$ & $\begin{array}{l}\text { Iron and folate } \\
\text { deficient }\end{array}$ & STVA \\
\hline 3 & $M / 46$ & Tiredness & Abnormal LFT & $13 \cdot 9$ & ND & PVA \\
\hline 4 & F/61 & Tireness & Abnormal LFT & $9 \cdot 3$ & Iron deficient & STVA \\
\hline 5 & $F / 73$ & $\begin{array}{l}\text { Manic/depressive } \\
\text { psychosis }\end{array}$ & $\begin{array}{l}\text { Abnormal thyroid } \\
\text { function }\end{array}$ & $10 \cdot 6$ & $\begin{array}{l}\text { Iron and folate } \\
\text { deficient }\end{array}$ & ND \\
\hline 6 & $F / 48$ & Tired/tender ribs & Arthralgias & $13 \cdot 1$ & $\begin{array}{l}\text { Folate } \\
\text { deficient }\end{array}$ & STVA \\
\hline 7 & $F / 17$ & $\begin{array}{l}\text { Painful/swollen } \\
\text { ankles }\end{array}$ & Arthralgias & $13 \cdot 7$ & ND & PVA \\
\hline 8 & $F / 45$ & $\mathrm{Nil}^{\star}$ & Leukocytopenia ${ }^{\star}$ & $12 \cdot 2$ & Iron deficient & STVA \\
\hline
\end{tabular}

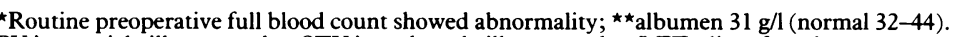
$\mathrm{PVA}=$ partial villous atrophy; STVA = subtotal villous atrophy; LFT = liver function test; $\mathrm{ND}=$ not done. phagus (The Binding Site, Birmingham, UK). Anti-gliadin antibody was detected by ELISA as described earlier ${ }^{11}$ except that commercial crude gliadin (Sigma Chemicals) was used as antigen source. Gliadin was dissolved in $70 \%$ ethanol/ $30 \%$ distilled water, and the undissolved fats and glutenins were discarded. Gliadin at a concentration of $10 \mu \mathrm{g} / \mathrm{ml}$ in $70 \%$ ethanol was used to coat the plates at room temperature overnight. Patient's sera were tested at a dilution of $1 / 100$.

\section{Results}

Clinical details of the eight R1-ARA seropositive adults are shown in Table I. The presenting complaints were vague, and in all but case 2 did not suggest gastrointestinal disease. Case 2 presented with weight loss and diarrhoea associated with hypoalbumenaemia $(31 \mathrm{~g} / \mathrm{dl})$ and mildly raised liver transaminase activities. Because of the patient's age, malignancy was suspected. Among the other cases, arthralgias were a common symptom. One patient was asymptomatic but was found to be leukopenic on a routine preoperative full blood test, justifying the initial autoantibody test. Although only three of the eight patients were anaemic, deficiency of iron and or folate at presentation was found in each of five patients tested. In all cases serum calcium was normal. Apart from case 2, normal serum albumen values were found. Abnormal liver function tests (typically, mild abnormalities of transaminase activities but a normal $\gamma$ glutamyl transferase value) were noted in five of eight patients. Each of these five had a raised alanine aminotransferase activity, with the highest value of $142 \mathrm{IU}$ (normal range, <35 IU) seen in patient six. The average alanine aminotransferase value before gluten free diet for these five patients was 85 IU. All seven cases, including the asymptomatic patient, felt better within eight weeks of starting a gluten free diet. Abnormalities of haematology and liver function returned to normal in all seven cases, taking up to six months to do this. R1-ARA, and anti-endomysial antibody disappeared and anti-gliadin antibody values fell to lie inside the normal range within six months of beginning a gluten free diet in the five patients for whom follow up samples were provided.

Table II shows that R1-ARA and partial R1 positive patients tended to be of IgA isotype, while the other ARA types tended to be of IgG isotype. Three of the five partial R1 positive sera became recognisable as R1-ARA when retested in the IgA specific test. These three sera were also IgA anti-endomysial antibody positive. This was not noted for any of the other non- $\mathrm{R} 1$ sera

TABLE II Seropositivity for IgA anti-gliadin antibody and IgA anti-endomysial antibody in relation to anti-reticulin antibody type

\begin{tabular}{|c|c|c|c|c|c|}
\hline \multirow{2}{*}{$\begin{array}{l}\text { Anti- } \\
\text { reticulin } \\
\text { type }\end{array}$} & \multirow{2}{*}{$\begin{array}{l}\text { No } \\
\text { tested }\end{array}$} & \multicolumn{2}{|c|}{ Immunofluorescence } & \multirow{2}{*}{$\begin{array}{l}\text { IgA anti- } \\
\text { gliadin } \\
\text { antibodies }\end{array}$} & \multirow{2}{*}{$\begin{array}{l}\text { IgA anti- } \\
\text { endomysial } \\
\text { antibodies }\end{array}$} \\
\hline & & $\operatorname{Ig} A$ & $I g G$ & & \\
\hline Rl & 5 & $5 / 5$ & $1 / 5$ & $5 / 5$ & $5 / 5$ \\
\hline Partial R1 & 5 & $3 / 5$ & $3 / 5$ & $3 / 5$ & $3 / 5$ \\
\hline R2 & 15 & $1 / 15$ & $14 / 15$ & $1 / 15$ & $0 / 15$ \\
\hline Rs & 15 & $2 / 15$ & $14 / 15$ & $1 / 15$ & $0 / 15$ \\
\hline Heterophile & 10 & $0 / 10$ & $10 / 10$ & $0 / 10$ & $0 / 10$ \\
\hline
\end{tabular}




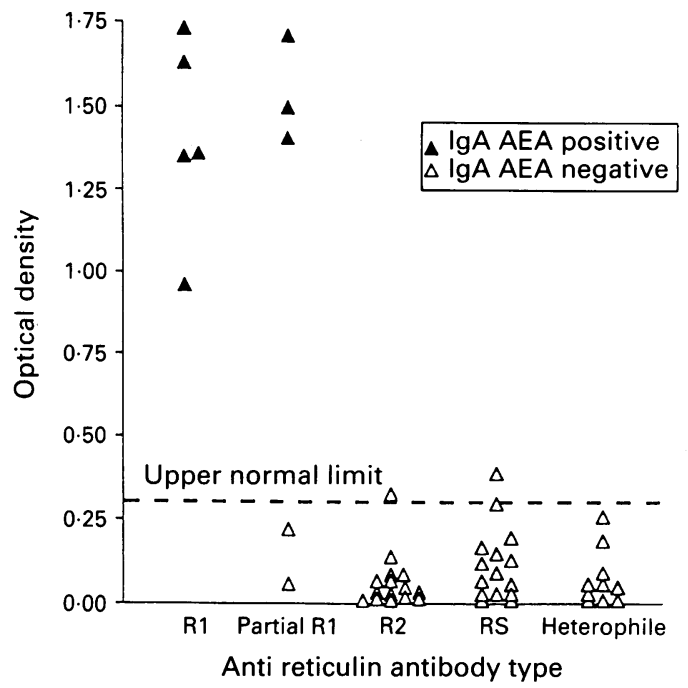

IgA anti-gliadin antibody ELISA titre in relation to antireticulin antibody type. AE $A=$ anti-endomysial antibody.

arising from the initial screen using a polyvalent anti-immunoglobulin reagent. All eight RlARA positive sera were also IgA anti-endomysial antibody and high titre IgA anti-gliadin antibody positive. None of the other 42 control sera were IgA anti-endomysial antibody positive, and only two of 42 were IgA anti-gliadin antibody positive. As shown in the Figure, high titre IgA antigliadin antibody was restricted to those sera which were IgA anti-endomysial antibody and R1-ARA positive. Table III shows the total number of newly diagnosed adult cases of coeliac disease diagnosed over the one year study period.

\section{Discussion}

We have screened a very large number (6532) of sera blind and have followed up patients who were R1-ARA positive, irrespective of their presenting symptoms. Our data show that the R1-ARA is an extremely reliable marker of coeliac disease. The diagnosis of gluten sensitive enteropathy in two of our seven patients may be disputed because these patients did not have follow up biopsies to show mucosal improvement as a result of the gluten free diet. All patients, however, admit to feeling much better after exclusing gluten from their diet, and without exception, abnormalities of liver function and haematology have returned to normal in all cases where abnormalities had been noted. Coeliac disease can present with vague symptoms of malaise. ${ }^{12}$ Arthralgias were common in our patients, and an association between coeliac disease and arthritis has been reported before. ${ }^{1314}$ In one case of juvenille rheumatoid

TABLE III Incidence of adult coeliac disease in this region

\begin{tabular}{lccl}
\hline & & $\begin{array}{l}\text { No of new adult cases of } \\
\text { coeliac disease }\end{array}$ \\
\cline { 3 - 4 } Hospital & $\begin{array}{l}\text { Local } \\
\text { population }\end{array}$ & $\begin{array}{l}\text { Identified } \\
\text { clinically }\end{array}$ & $\begin{array}{l}\text { Identified } \\
\text { serologically }\end{array}$ \\
\hline Hinchinbrooke & 140000 & 7 & 2 \\
The West Suffolk & 240000 & 14 & 0 \\
Addenbrooke's & 290000 & 12 & 2 \\
Norfolk and Norwich & 490000 & 25 & 3 \\
Total & 1160000 & 58 & 7 \\
\hline
\end{tabular}

arthritis, R1-ARA was present in joint aspirate. ${ }^{14}$ None of our patients presented with the stigmata of recognised arthritic diseases, there was no clear pattern of joint involvement (Table I), and symptoms resolved speedily on the gluten free diet. The trend towards testing rheumatology clinic sera for anti-nuclear antibody on cell monolayers (on which R1-ARA are not detected) rather than on rat liver tissue sections may lead to these atypically presenting coeliac disease cases being missed.

Had it not been for the finding of R1-ARA in our cases, the diagnosis of coeliac disease would have been at best delayed, or worse, missed altogether. This might have exposed the patients to an increased risk of gastrointestinal malignancy. ${ }^{8}$ There are two previous studies similar to ours. ${ }^{12}$ 15 Both quote impressive results using R1ARA fortuitously noted in the course of routine autoantibody testing to diagnose atypically presenting coeliac disease in adults. Collin et $a l^{12}$ found 51 R1-ARA positive sera when testing 17000 adult sera over a three year period. Of 30 patients who were successfully biopsied, only 18 proved to have coeliac disease. The remaining 12 had normal jejunal biopsy specimens and proved to have IgG and not IgA R1-ARA. Sixteen of the 18 patients with coeliac disease had IgA R1ARA. Restricting biopsy to patients who were IgA positive would thus have yielded similar results to ours. Watson et $a l^{15}$ identified 291 suspicious sera while performing autoantibody testing but did not provide details of the reticulin antibody class. They retested their sera for antigliadin antibody and focused attention on the anti-gliadin antibody positive patients. Eighteen underwent jejunal biopsy and each of the $13 \operatorname{IgA}$ anti-gliadin antibody positive patients proved to have coeliac disease while the five with IgG but not IgA anti-gliadin antibody had normal biopsy specimens. The difference between our study and the preceeding two seems to be that by using IgA anti-endomysial antibody to confirm gluten sensitivity in our R1-ARA seropositive patients, we have improved the diagnostic accuracy to $100 \%$. By contrast, use of IgA anti-gliadin antibody to confirm gluten sensitivity is unrelable. ${ }^{12}$ This point is clear from study of patients with IgA nephropathy ${ }^{16}$ which shows that IgA antigliadin antibody is not infrequently found in patients who do not have coeliac disease when sent for jejunal biopsy. Anti-endomysial antibody was associated only with R1-ARA and not with the other ARA types. To our knowledge, no-one else has checked whether the various ARA types interfere in the endomysial antibody test. The copresence of both anti-gliadin antibody and anti-endomysial antibody (of IgA class) will clearly help those who are inexperienced in recognising the $\mathrm{R} 1$ pattern.

During the study period 58 new adult cases of coeliac disease (excluding our seven biopsy proved cases) were diagnosed in the four East Anglian hospitals that request autoantibody studies from us. These four hospitals serve a population of $1 \cdot 16$ million (note that this figure includes children and adults). Serological identification of cases of occult coeliac disease allowed us to increase the incidence in our local population by $12 \%$. As R1-ARA screening using poly- 
valent rather than $\operatorname{IgA}$ specific reagents has a sensitivity in our hands of only $50 \%$ in the context of diagnosing coeliac disease, ${ }^{4}$ and as we screened only 6532 sera, coeliac disease is likely to be appreciably underdiagnosed. The association between coeliac disease and selective IgA deficiency will result in negative IgA R1-ARA and may further exaggerate the underdiagnosis. Population screening for gluten sensitivity has been advocated but it is uncertain that it will be cost efficient in adults. The approach we have used is inexpensive and amounts to audit of samples being processed anyway. Our high diagnostic yield may in part reflect the fact that the sera we test for autoantibodies come from patients who are ill. Screening healthy people may prove less productive.

R1-ARA in this study was highly specific for gluten sensitive enteropathy. So what of the previous reports ${ }^{56}$ that R1-ARA is not specific? Rizzetto and Doniach ${ }^{10}$ described five types of ARA, and recognition of the R1-ARA can be difficult for non-experts. Hence Rl-ARA is often misreported or worse ignored, particularly if the autoantibody test is requested for reasons unconnected with gluten sensitivity. Also, initial studies did not break down seropositive sera according to isotype. Another factor is that when atypically presenting or clinically silent gluten sensitive enteropathy coexists with or is mistaken for some other diagnosis, apparent 'false positives' may be reported. Because coeliac disease can present with atypical symptoms subclinical gluten sensitive enteropathy cannot be excluded unless patients with R1-ARA undergo small intestinal biopsy. The fact that R1-ARA has been reported in relatives of known coeliac disease patients with a normal jejunal biopsy specimen who subsequently go on to develop gluten sensitive enteropathy ${ }^{17}$ cautions us that even in the face of a normal jejunal biopsy specimen the possibility of 'latent' coeliac disease means that long term follow up of patients with serum positive for R1-ARA and normal jejunal biopsy tissues is appropriate. We believe that these factors have compounded the false belief that the R1-ARA is diagnostically unreliable. Our data suggest that whatever clinical circumstances, the presence of serum IgA R1-ARA, particularly when coexisting with IgA antiendomysial antibody, is an absolute indication for jejunal biopsy to confirm gluten sensitive enteropathy.

1 Editorial. Diagnosis of coeliac disease. Lancet 1991; i: 590-1.

2 Ferreira M, Lloyd Davies S, Butler M, Scott D, Clark M, Kumar P. Endomysial antibody: is it the best screening test for coeliac disease? Gut 1993; 33: 1633-7.

3 Seah PP, Fry L, Hoffbrand AV, Holborow EJ. Tissue autoantibodies in dermatitis herpetiformis and adult coeliac disease. Lancet 1971; i: 834-6.

4 Unsworth DJ, Walker-Smith JA, Holborow EJ. Gliadin and reticulin antibodies in childhood coeliac disease. Lance 1983; i: 874-5.

5 Alp MH, Wright R. Autoantibodies to reticulin patients with steatorrhoea, coeliac disease, and Crohn's diease, and their relation to immunoglobulins and dietary antibodies. Lancet 1971; ii: 682-5.

6 Eade OE, Lloyd RS, Lang C, Wright R. IgA and IgG reticulin antibodies in coeliac and non-coeliac patients. Gut 1977; 18: 647-50.

7 Mäki M, Hällström O, Vesikari T, Visakorpi J. Evaluation of a serum IgA-class reticulin antibody test for the detection of a serum IgA-class reticulin antibody test for the detect

8 Holmes GKT, Prior P, Lane MR, Pope D, Allan RN. Malignancy in coeliac disease: effect of a gluten free diet. $G u$ 1989; 30: 333-8

9 Walker-Smith JA, Guandalini S, Schmitz J, Schmerling Visakorpi JK. Revised criteria for the diagnosis of coeliac disease. Arch Dis Child 1990; 65: 909-11.

10 Rizzetto M, Doniach D. Types of reticulin antibodies detected in human sera by immunofluorescence. $\mathcal{F}$ Clin Path 1973 26: $841-7$

11 Unsworth DJ, Leonard JN, McMinn RMH, Swain AF, Holborow EJ, Fry L. Anti-gliadin antibodies and small intestinal mucosal damage in dermatitis herpetiformis. Brf Dermatol 1981; 105: 653-8.

12 Collin P, Hällström O, Mäki M, Viander M, Keyrilainen O. Atypical coeliac disease found with serological screening. Scand f Gastroenterol 1990; 25: 245-50.

13 Bourne J, Kumar P, Huskisson E, Mageed R, Unsworth D, Wojtulewski J. Arthritis and coeliac disease. Ann Rheum Dis 1985; 44: 592-8

14 Mäki M, Hällstrüm O, Verronen P, Reunala T, Lahdeahö M Holm K, Visakorpi J. Reticulin antibody, arthritis an coeliac disease in children. Lancet 1988; i: 479-80.

15 Watson RGP, McMillan SA, Dickey W, Biggart JD, Porter KG. Detection of undiagnosed coeliac disease with atypical features using antireticulin and antigliadin antibodies. QF Med 1992; 84: 713-8.

16 Sategna-Guidetti C, Ferfoglia G, Bruno M, Putitano R Roccatello D, Amore A, Coppo R. Do IgA antigliadin and IgA antiendomysium antibodies show there is latent coeliac disease in primary IgA nephropathy? Gut 1992; 33: 476-8.

17 Mäki M Holm K Lipsanen V, Hällström O, Viander M Collin P, Savilahti E, Koskimies S. Serological markers and Collin P, Savilahti E, Koskimies S. Serological markers and
HLA genes among healthy first-degree relatives of patients whA genes among healthy first-degree relat 